\title{
OSSEOINTEGRATED IMPLANTS VERSUS ZIRCONIUM MUCOSAL INSERTS IN COMPLETE DENTURE PATIENTS
}

\author{
Fardos N Rizk* and Sara F El Shafei**
}

\begin{abstract}
Purpose: To evaluate the effect of osseointegrated implants versus mucosal inserts used for retention of complete dentures.

Materials and Methods: Twelve completely edentulous patients were selected for this study and divided into two groups of six. Group I received implant retained maxillary overdentures, while group II received maxillary overdentures retained by muchor zirconium mucosal inserts. Bone changes in both groups were evaluated using cone beam ct at insertion and after six and twelve months.
\end{abstract}

Results: The results showed that the bone changes produced in mucosal overdenture wearers were greater than those produced in implant overdenture wearers.

Conclusion: Zirconium mucosal inserts caused more bone changes than osseointegrated implants.

\section{INTRODUCTION}

Edentulism has always been a considerable obstacle facing patients and dentists alike. Conventional complete dentures are not the ultimate solutions they promise to be, and other answers have long been sought. However, multiple factors interfere in the success of a complete denture, some of which are highly subjective like the patientdentist relationship and the patient's psychological personality. ${ }^{(1)}$
Construction of a retentive complete denture for edentulous patients is one of the goals of prosthodontists. An unretentive denture disturbs all other goals such as speech, mastication and in turn affects patient's psychology. (2)

It has been suggested in some studies that denture retention affects the patient's satisfaction with maxillary complete dentures more than many other important factors. ${ }^{(3)}$

Henceforth, the attempts to improve complete denture retention have been on the rise and are an

\footnotetext{
* Professor of Removable Prosthodontics, Vice Dean of The Faculty of Dentistry, The British University in Egypt, Head of Removable Prosthodontics Department.

** Lecturer of Removable Prosthodontics, The British University in Egypt
} 
ultimate target to prosthodontists. The introduction of implant overdentures has proved to be a revolutionary solution for this problem. They have been shown as a favorable treatment option for patients with persistent complaints of poor retention and stability of their conventional maxillary denture. Besides sufficient retention and stability, proper phonetics, aesthetics and hygiene access can be achieved with maxillary implant overdentures. ${ }^{(4)(5)}$

Dental implants have long been classified into several diverse and widely accepted classifications. In the scope of this study we will discuss only two types of implants, classified under the category of Implant Position into; endosseous implants, and mucosal inserts.

Endosseus implants are now the most widely used implant type, with various designs and compositions. ${ }^{(6)}$ Whereas mucosal inserts were often used since the $1940 \mathrm{~s}$, their use has declined in the last two decades, but has recently re-emerged again as a conservative treatment option where maxillary denture retention is questionable. ${ }^{(7)}$

Although significant advances and progresses are being made in endosteal implants, some patients are still unable to use them. Patients where gross resorption of the maxillary alveolar ridge has occurred often cannot insert endosteal implants conventionally and require complex surgical procedures to do so, like bone grafting, thereby increasing the complexity and morbidity of the procedure. In these cases, the use of mucosal inserts for maxillary denture retention seem like a viable treatment option, and a conservative alternative to endosteal implants.

In this study we have attempted to compare the effect of zirconium mucosal inserts versus that of endosteal implants on maxillary overdenture supporting structures.

\section{MATERIALS AND METHODS}

Twelve completely edentulous patients were selected from the outpatient clinic of the Removable Prosthodontics Department, Faculty of Dentistry, The British University in Egypt. All the patients signed an informed consent. Patients' age ranged from 45 to 60 years. Exclusion criteria included patients with systemic diseases affecting bone quality or bone resorption, Temporomandibular joint dysfunction, parafunctional habits, patients undergoing radiotherapy or chemotherapy, heavy smokers, and vulnerable groups like psychologically unstable patients and unmotivated patients. ${ }^{\left({ }^{()(9)}\right.}$

The thickness of the maxillary mucosa of each patient was measured at this stage. After giving the patient infiltration anaesthesia, an endodontic file with a stopper was used to measure the thickness of the mucosa in a technique very similar to ridge mapping. This was to ensure that all patients included in this study had a minimum mucosal thickness of $3.75 \mathrm{~mm}$.

The patients were then divided into two groups, made of six patients each.

Group I received complete implant-retained maxillary overdentures, retained by four endosteal implants.(figures 1 and 2)

Group II received complete maxillary overdentures fitted with eight muchor mucosal anchors, four on each side on the crest of the ridge in the denture fitting surface in the positions of the first Premolar, Second premolar, First molar and second molar. (figure 3)

Construction of complete dentures was carried out for all patients in the conventional manner. Preliminary impressions were recorded using alginate impression material (Cavex, Holland) and poured in dental stone, upon which special trays were constructed and the final impressions recorded using rubberbase material.(Speedex,Coltene, Whaledent AG, Switzerland) 


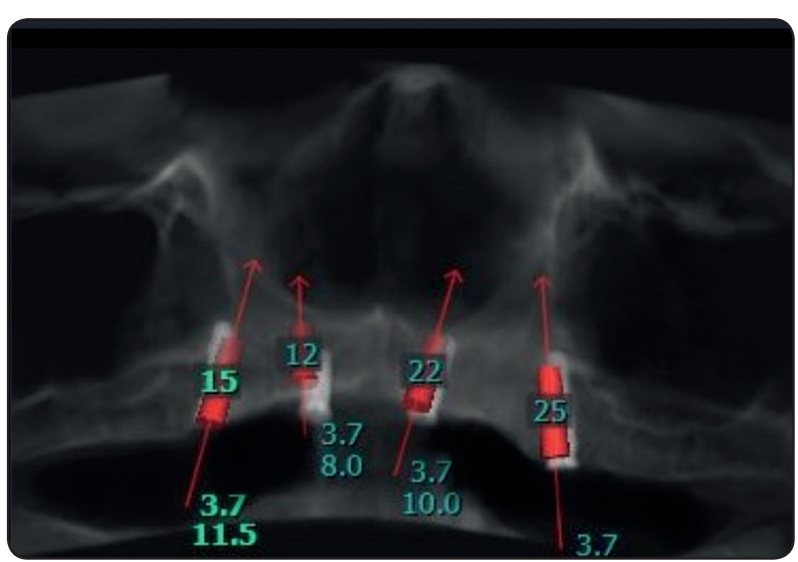

Fig. (1)

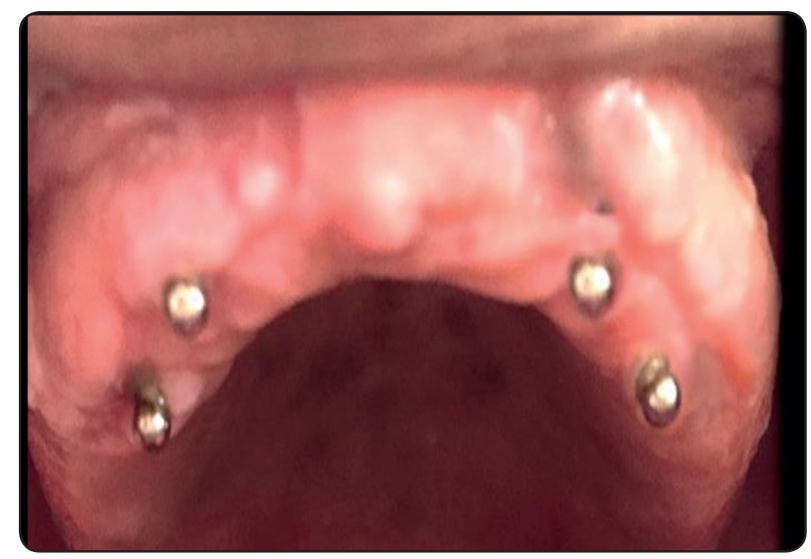

Fig. (2)

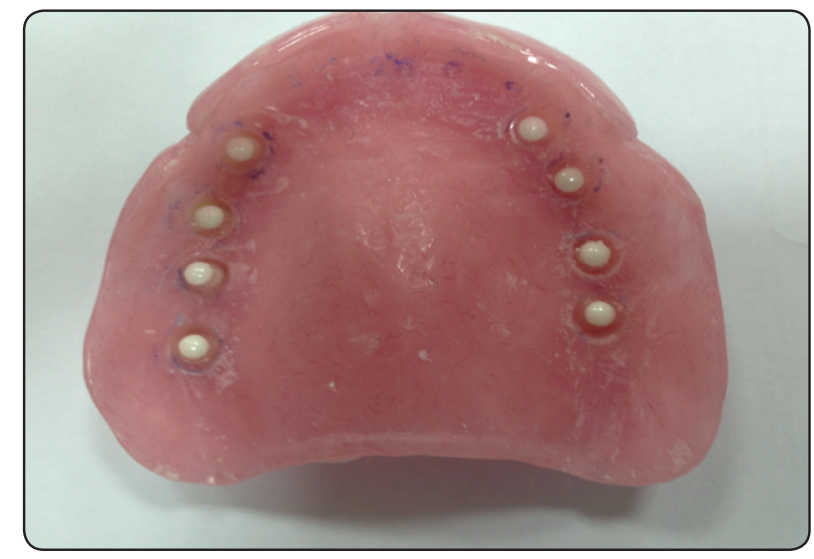

Fig. (3)
Maxillomandibular relationships were recorded, the trial bases mounted and setting up of teeth carried out, then the try in was done in the patients' mouths. Denture processing was then made and proper occlusal adjustment was carried out intraorally.

Group I: Four endosteal maxillary implants (Neobiotech, Korea) were inserted in the patients mouths, guided by a surgical stent, in the areas of the canines and the first molars. Single stage surgical technique was used in implant insertion.

Following implant insertion, healing collars were screwed onto the implants, and the patients were asked to wear their dentures normally. Ten days postoperatively, the patients were recalled, and ball and socket attachments (Neobiotech, Korea) were mounted on each implant. Relief was carried out in the denture fitting surface, and the attachment housings were picked up using chairside direct pick up technique.

Group II: Group II patients received complete dentures where each maxillary denture was fitted with eight muchor mucosal anchors (Dyna, Netherlands), four on each side on the crest of the ridge in the denture fitting surface in the positions of the first premolar, second premolar, first molar and second molar.

Prior to insertion, the predetermined sites where the mucosal inserts will be placed were dried with a sterile gauze in the patient's mouth and marked with indelible pen and the maxillary denture was seated firmly in place so that these markings were transferred to the fitting surface of the denture. Using the dental surveyor and the laboratory drill provided with the muchor set, the predetermined muchor anchor sites were prepared in the fitting surface of the denture, and the mucosal anchors were inserted in a parallel position. The anchors were fixed in place using a small amount of pink self cured arylic resin (Acrostone, England), and any excess resin was carefully removed. Temporary filling material was used to block out all undercuts 
surrounding the muchor anchors, and pink wax was used to block out all other undercuts in the fitting surface of the denture. The denture fitting surface was brushed with separating medium, then dental stone was poured into the denture fitting surface to form a stone model, upon which a surgical drilling guide was constructed using vacuum forming machine. A size 3 round bur was used for drilling in the positions of the muchor anchors, to create holes in the drilling guide corresponding to the exact positions of the muchor anchors.

Using the drilling guide, and a dentist drill provided with the muchor set, drilling was carried out intraorally. Denture adhesive (Corega,Ireland) was then added to the denture's fitting surface and the denture fitted into the patient's mouth, and the patient was instructed not to remove the denture for three days.

Radiographic follow up was carried out for both groups using cone beam ct at insertion, after 6 months and after 12 months. To standardize data collection, the bone level was measured around each implant or mucosal insert from the buccal, lingual, mesial and distal aspects, then an average of these readings was taken. This was repeated at the time of insertion, after 6 months and after 12 months.

\section{RESULTS}

Statistical analysis was performed using IBM SPSS Statistics Version 2.0 for Windows. Data was presented as mean and standard deviation (SD). The significance level was set at $\mathrm{P} \leq 0.05$. KolmogorovSmirnov and Shapiro-Wilk tests were used to assess data normality.

Wilcoxon Signed-Rank test (non-parametric test, 2 related samples) was used to compare the bone level at the different follow-up periods with each study group. Independent t-test (parametric test, 2 independent samples) was conducted to compare the bone level between osseointegrated implants and muchor system groups at each follow-up period.
One-Way ANOVA followed by Tukey's post-hoc test were used to compare bone changes at different time intervals within osseointegrated implants group. Kruskal Wallis test followed by MannWhitney U (non-parametric test, 2 independent samples) test were conducted to compare bone changes at different time intervals within muchor system group. Independent t-test and Mann-Whitney $\mathrm{U}$ test were used for intergroup comparisons at each time interval.

\section{Comparison of bone changes within osseointe- grated implants and Muchor system groups at different time intervals:}

TABLE (1): Mean \pm Standard Deviation (SD) and P value for the comparison of bone changes (mm) within osseointegrated implants and Muchor system groups at different time intervals.

\begin{tabular}{lccc}
\hline & $\begin{array}{c}\text { Osseointegrated } \\
\text { Implants }\end{array}$ & $\begin{array}{c}\text { Muchor } \\
\text { System }\end{array}$ & $\begin{array}{c}\text { P- } \\
\text { value }\end{array}$ \\
\cline { 2 - 3 } & \multicolumn{2}{c}{ Mean \pm SD } & \\
\cline { 1 - 2 } $\begin{array}{l}\text { Baseline - } \\
\text { 6 months }\end{array}$ & $0.47 \pm 0.12^{\mathrm{b}}$ & $0.67 \pm 0.36^{\mathrm{b}}$ & $0.000^{*}$ \\
\hline $\begin{array}{l}\text { 6 months - } \\
\text { 12 months }\end{array}$ & $0.36 \pm 0.09^{\mathrm{b}}$ & $0.58 \pm 0.36^{\mathrm{c}}$ & $0.006^{*}$ \\
\hline $\begin{array}{l}\text { Baseline - } \\
\text { 12 months }\end{array}$ & $0.84 \pm 0.13^{\mathrm{a}}$ & $1.25 \pm 0.32^{\mathrm{a}}$ & $0.000^{*}$ \\
\hline P-value & $0.000^{*}$ & $0.000^{*}$ & \\
\hline
\end{tabular}

$*$ : significant at $P \leq 0.05$

Means with different superscript letters within the same column are statistically significantly different at $P \leq 0.05$

The results show that the bone changes produced in group II patients around the mucosal inserts were significantly higher than the amount of bone loss that occurred in group I around the endosteal implants. 


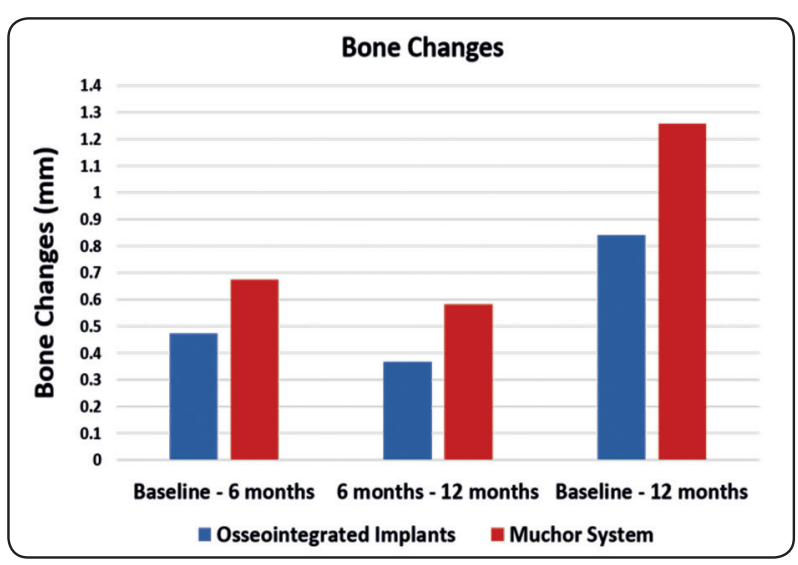

Fig. (4)

\section{DISCUSSION}

In this study, all patients with systemic diseases affecting the bone, temporomandibular joint dysfunction or parafunctional habits have been excluded to avoid the effects these variations may cause to the crestal bone loss surrounding the implants or the zirconium inserts.

All the selected patients had a minimum maxillary mucosal thickness of $3.75 \mathrm{~mm}$ in order to be able to accommodate the insertion of the muchor inserts, without resting on the periosteum. This was done to avoid exerting pressure on the periosteum which might deprive the underlying bone from sufficient nutrition.

The results of this study showed that the bone loss that occurred in group II patients around the mucosal inserts were significantly higher than the amount of bone loss that occurred in group I around the endosteal implants.

This was in accordance with certain studies which stated that very little bone resorption took place in the bone height between implant placement and during a follow up period of 10 years. The study suggested that the alveolar ridge preservation was a consequence of physiologic stress distribution from implant placement. ${ }^{(10)}$

In contrast, other studies suggested that since implants associated with the implant overdentures provide stronger biting force, they could potentially concentrate hydrostatic stress and cause greater residual ridge resorption. ${ }^{(11)(12)(13)}$

Furthermore, other studies revealed that the use of intramucosal inserts resulted in bone resorption localized to the receptor sites. Widening of the receptor sites was found, particularly in patients who brux, and the importance of achieving even occlusion in all cases was stressed. These studies also suggested that regular denture relining procedures may actually decrease the resultant bone loss at the receptor sites. Moreover, it was mentioned that the studs must pass through the mucosa and approach the bone in a perpendicular direction, so that the forces falling on the bone Haversian systems are perpendicular and therefore efficiently dissipated, instead of causing bone loss. ${ }^{(14)(15)(16)}$

\section{CONCLUSION}

Zirconium mucosal inserts overdentures produced more bone changes over time than osseointegrated implants overdentures.

\section{REFERENCES}

1. Boerrigter EM, Geertman ME, van Oort RP, Bouma J, Raghoebar GM, van Waas MA, et al. Patient satisfaction with implant retained mandibular overdentures. A comparison with new complete dentures not retained by implants - a multicentre randomized clinical trial. $\mathrm{Br} \mathrm{J}$ Oral Maxillofac Surg. 1995; 33: 282-8

2. Rizk FN. Effect of different border molding materials on complete denture retention. C D J 2008; 24: 415-20

3. Kovac Z, Troscot Z, Uhac I, Cabov T, Lajnert V, Pavicic D, Filipovic-Zore I, Tariba P. Multivariate analysis of different factors affecting the patient general satisfaction with complete dentures. CollAntropol 2012; 3: 791-94

4. Visser A, Raghoebar GM, Meijer HJ, Vissink A. Implant retained maxillary overdentures on milled bar suprastructures: a 10-year follow-up of surgical and prosthetic care and aftercare. Int J Prosthodont 2009; 22:181-192.

5. Raghoebar GM, Meijir H, Slot W, Huddelston Slater J,Vissink A. A systematic review of implant-supported overdentures in the edentulous maxilla, compared to the mandible: How many implants? Eur J Oral Implantol 2014;7:191-201. 
6. Feine J, Heydecke G. Implant overdentures versus conventional dentures. In: Feine J, Carlsson G eds. Implant Overdentures: The Standard of Care for the Edentulous Patients. Chicago: Quintessence publishing Co Inc, 2003.

7. Rizk F N. Effect of different abutment designs on implant- supported overdenture supporting structures. $\mathrm{PhD}$ Thesis 2007

8. Sueda S, Fueki K, Sato $\mathrm{S}$ et al. Influence of working side contacts on masticatory function for mandibular distal extension removable partial dentures. J Oral Rehabil 2003 30: $301-306$

9. Singhal S, Chand P, Singh BP et al. The effect of osteoporosis on residual ridge resorption and masticatory performance in denture wearers. Gerodontology 2012 29: 1059-1066

10. Mosnegutu A, Wismeijer D, Geraets W. Implant-Supported Mandibular Overdentures Can Minimize Mandibular Bone Resorption in Edentulous Patients: Results of a Long-Term Radiologic Evaluation.Int J Oral Maxillofac Implants 2015;30:1378-1386.
11. Ahmad R, Beng J, Abu -Hassan M, Li Q, Swain M V. Investigation of Mucosa-Induced Residual Ridge Resorption Under Implant-Retained Overdentures and Complete Dentures in the Mandible. Int J of Oral Maxillofac Implants. 2015;30:657-666.

12. Boven GC, Rhagoebar GM, Vissink A, Meijer HJA. Improving masticatory performance, bite force, nutritional state and patient's satisfaction with implant overdentures: a systematic review of the literature. J Oral Rehab 2015; 42: 220-233.

13. Chen J, Ahmad R, Suenaga H, Li W, Swain M, Qing L. A comparative study on complete and implant retained denture treatments - A biomechanics perspective. J Biomech 2015;48:512-519

14. Hoad-Reddick G, Grant A. Intramucosal inserts - time for a reevaluation? Ouintessence Int 1989:20:879-883.

15. Cranin AN, Cranin SL: the intramucosal insert.a method of miUillLiry denlure stabilizalion. / Am Dent As.wc I958;57:188193.

16. Cranin AN, Cranin SL: The intramticosa! insert: a ten-year progress report. J Am Dent A.'isoc 1965;7Ü:621-627. 